This item was submitted to Loughborough's Research Repository by the author.

Items in Figshare are protected by copyright, with all rights reserved, unless otherwise indicated.

\title{
A three-zone heat-release rate model for dual-fuel combustion
}

PLEASE CITE THE PUBLISHED VERSION

http://dx.doi.org/10.1243/09544062JMES1955

\section{PUBLISHER}

Sage / (C IMechE

\section{VERSION}

AM (Accepted Manuscript)

\section{LICENCE}

CC BY-NC-ND 4.0

\section{REPOSITORY RECORD}

Stewart, Jill, and Andrew Clarke. 2019. "A Three-zone Heat-release Rate Model for Dual-fuel Combustion". figshare. https://hdl.handle.net/2134/8988. 
This item was submitted to Loughborough's Institutional Repository (https://dspace.lboro.ac.uk/) by the author and is made available under the following Creative Commons Licence conditions.

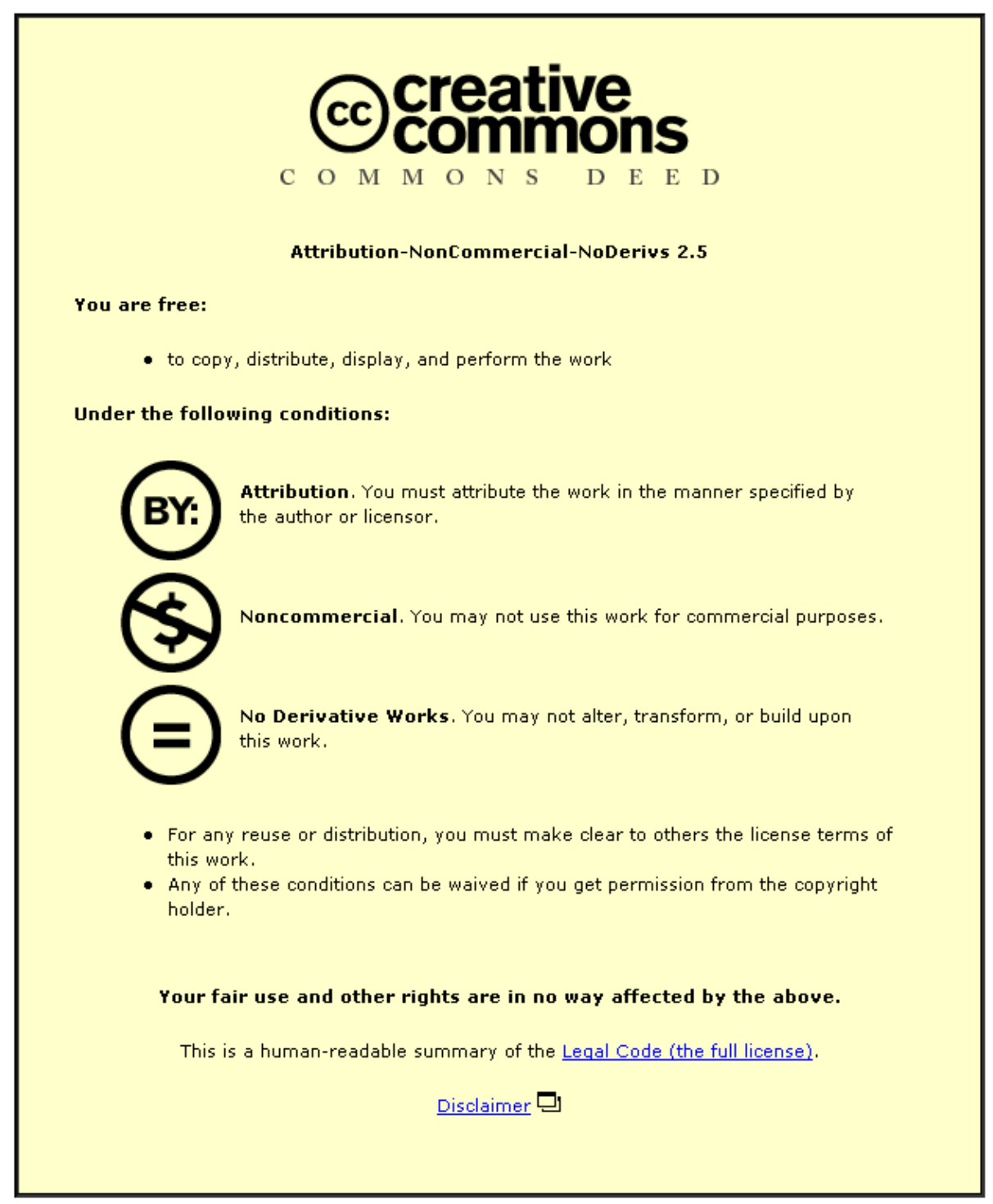

For the full text of this licence, please go to: http://creativecommons.org/licenses/by-nc-nd/2.5/ 
Editorial Manager(tm) for Proceedings of the Institution of Mechanical Engineers, Part C, Journal of Mechanical Engineering Science

Manuscript Draft

Manuscript Number:

Title: A Three-Zone Heat-Release Rate Model For Dual Fuel Combustion

Article Type: Paper

Section/Category: Thermodynamics and Heat Transfer

Keywords: Heat Release Analysis; Dual Fuel Engines.

Corresponding Author: Dr Andrew Clarke,

Corresponding Author's Institution: University of Loughborough

First Author: Jill Stewart, MEng PhD

Order of Authors: Jill Stewart, MEng PhD; Andrew Clarke

Abstract: Dual-fuel engines are modified compression ignition engines where the primary fuel source is provided by a gaseous fuel, and ignition is provided by a reduced quantity of diesel: the pilot. The generally accepted description of the subsequent combustion process is that initially, around half of the pilot will burn and entrain some gaseous fuel in an overall rich process. Then the remaining pilot fuel burns with an increasing amount of the primary fuel until the final stage where a flame propagation process engulfs the remaining gaseous fuel.

In this paper a three-zone model will be derived, benchmarked against data obtained for diesel combustion, and then applied to experimental data from a dual-fuel test program. The three-zone model will also be used to investigate the assumptions made regarding the mechanism of dual-fuel combustion proceeding in three-stages. It will be demonstrated that evidence was scant in support of the accepted description of three stages of dual-fuel combustion in a direct injection engine. The conclusion of this work is that that the dual-fuel combustion may be better considered as a diesel combustion process, where the gaseous fuel modifies the reaction zone surrounding each igniting droplet of the pilot fuel. 
Wolfson School of Mechanical and Manufacturing Engineering Loughborough University Leicestershire LE11 3TU UK

Switchboard: +44 (0)1509 263171

The Editor

Journal of Mechanical Engineering Science

Institution of Mechanical Engineering

Professional Engineering Press

\section{Loughborough University}

$7^{\text {th }}$ September 2009

Dear Editor,

\section{Re: Submission of Paper to IMechE Part C}

Please find attached electronically a technical paper for consideration for publication in the IMechE Part C Journal of Mechanical Engineering Science. At present dual fuel engines are being investigated as part of the UK's $\mathrm{CO}_{2}$ reduction plan. I feel that this paper is timely as it allows a more in depth understanding of the combustion phenomena occurring within the cylinder.

My contact details as corresponding author for the submission are:

Dr Andrew Clarke

Wolfson School of Mechanical and Manufacturing Engineering

Loughborough University

Loughborough

Leicestershire.

LE11 3TU

Tel 01509227522

Email a.clarke@lboro.ac.uk

Yours faithfully,

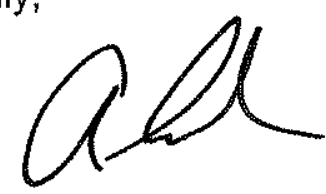

Dr Andrew Clarke

CEng MIMechE 


\title{
A THREE-ZONE HEAT-RELEASE RATE MODEL FOR DUAL-FUEL COMBUSTION
}

\author{
J. Stewart ${ }^{1}$ and A. Clarke ${ }^{2 \#}$ \\ 1 School of Computing, Science and Engineering, The University of Salford, Greater Manchester M5 4WT \\ 2 Wolfson School of Mechanical and Manufacturing Engineering, Loughborough University, LE11 3TU \\ \# Corresponding Author a.clarke@1boro.ac.uk
}

\section{ABSTRACT}

Dual-fuel engines are modified compression ignition engines where the primary fuel source is provided by a gaseous fuel, and ignition is provided by a reduced quantity of diesel: the pilot. The generally accepted description of the subsequent combustion process is that initially, around half of the pilot will burn and entrain some gaseous fuel in an overall rich process. Then the remaining pilot fuel burns with an increasing amount of the primary fuel until the final stage where a flame propagation process engulfs the remaining gaseous fuel.

In this paper a three-zone model will be derived, benchmarked against data obtained for diesel combustion, and then applied to experimental data from a dual-fuel test program. The three-zone model will also be used to investigate the assumptions made regarding the mechanism of dual-fuel combustion proceeding in three-stages. It will be demonstrated that evidence was scant in support of the accepted description of three stages of dual-fuel combustion in a direct injection engine. The conclusion of this work is that that the dual-fuel combustion may be better considered as a diesel combustion process, where the gaseous fuel modifies the reaction zone surrounding each igniting droplet of the pilot fuel.

\section{INTRODUCTION}

A 'dual-fuel' engine is a compression ignition (CI) engine where the primary (gaseous) fuel is pre-mixed with air prior to, or immediately upon, its admission to the combustion chamber. This homogenous mixture is ignited by a small quantity of diesel fuel called the 'pilot', which is injected towards the end of the compression stroke. Karim [1] described the dual-fuel combustion process as proceeding in three stages after ignition. 
- $\quad$ Stage I is due to the premixed combustion of approximately half of the pilot fuel and a small amount of gaseous fuel entrained within it.

- Stage II is due to diffusive combustion of the rest of the pilot and the rapid burning of gaseous fuel in the immediate surroundings. This stage is analogous to the premixed diesel combustion phase [2].

- $\quad$ Stage III is due to the remainder of the premixed gaseous fuel-air charge burning. This stage is analogous to the diffusion burning phase in a diesel engine [2].

According to Karim's description, when low concentrations of gaseous fuel are used, most of the energy release should be due to the pilot and primary fuel entrained by the pilot injection (figure 1a). This effect would be particularly pronounced at low loads. At high loads, or high gaseous fuel concentrations, Karim argued that stages I and II would merge, and as flame propagation would be more stable, most of the energy release would result from stage III (figure 1b).

\section{$<$ Figure 1a and 1b $>$}

Dual-fuelling strategies can involve one of two methods: The first and best-known approach is the injection of a small quantity of diesel to provide a means of igniting a lean gaseous fuel-air charge, with the objective to maximise the use of the gaseous fuel and reduce operating cost with respect to fuel [3]. The second approach fumigates a small quantity of gaseous fuel to the incoming air of a diesel engine, and was proposed in order to increase engine power output [4]. In either case, the penalty of a poorly optimized fuelling strategy is an increase in emissions of carbon monoxide and unburned hydrocarbons [5]. However, the benefit of dual-fuel is its potential to reduce problematic diesel engine emissions, as it provides a mechanism by which the well known NOx/smoke trade-off [2] can be manipulated. Before this goal can be attained, and before dual-fuel engines can be deployed in practical applications, the complex dual-fuel combustion process must be better understood.

Engine-out emissions data (a major improvement objective) provides some of the information required to better understand dual-fuel combustion processes, but knowledge of the timedevelopment of thermodynamic variables is also required. This data is obtained by heatrelease analysis, which solves the in-cylinder pressure record for heat-release rate and mass fraction burned via the first law of thermodynamics and ideal gas equations of state. As a 
diagnostic method, heat-release rate analysis of in-cylinder pressure data is possibly the most widely used and powerful combustion diagnostic tool [6], yielding experimental data that would otherwise require advanced instrumentation and complex installations. Furthermore, application of heat-release rate analysis to dual-fuel engines has been limited.

Single-zone models represent the simplest approach to heat-release analysis. The single-zone is assumed to coincide with the combustion chamber volume, assuming that all species behave as ideal gasses with uniform pressure and temperature throughout the control volume. Terms are included for work, chemical energy change and heat transfer to the walls, but not for spatial variation (for example, see [2,5,6-9]). This method has formed the basis for two dual-fuel heat-release rate analysis models. The first was proposed by Khan [10], where the proportion of heat-released due to the gaseous fuel and the diesel was determined by defining an 'equivalent-fuel' comprised of the gaseous fuel and diesel using their relative proportions at the start of the calculation. This study lead Karim [3] to propose the widely-accepted three-stage description of the dual-fuel combustion process (see above). The second example of a single-zone model was proposed by Pirouzpanah[11], and rests upon this three-stage description, whereby a modified version of the Whitehouse and Way [12] combustion pattern was applied to determine the mass of both diesel and the gaseous fuel that was burned in each time step.

More recently, Kishnan et al. [13] returned to Khan's equivalent-fuel definition (similar to[10]) to derive a heat-release rate model that divides the combustion chamber into two zones representing burned and unburned gasses, so that the temperature and mass of each zone can be evaluated simultaneously in addition to the heat-release rate. The mixtures in each zone were assumed to be in thermodynamic equilibrium, with a uniform pressure across the combustion chamber. This work showed that for methane substitution levels of up to 50 $\%$ (by energy content), the magnitude of initial heat-release peaks at first increase with increasing gaseous-fuel substitution levels (in agreement with [11]). Beyond this $50 \%$ level the results become contradictory, as Pirouzpanah [11] found that initial peaks continued to increase whereas Kishnan et al. [13] found them to decrease. The differences are caused by the alternative assumptions made regarding the mass-burning rate. In Pirouzpanah's model, a combustion model was assumed, and consistently applied, irrespective of the relative proportions of the two fuels. Kishnan [13] made no assumptions regarding a combustion pattern, but employed Khan's equivalent-fuel method [10]. 
These contradictory analyses formed the motivation for the research described in this paper, where the assumptions regarding the mechanisms by which the two fuels burn are revisited. In order to carry out this investigation, a three-zone heat-release rate model is proposed that is conceptually closer to the physical processes occurring within dual-fuel engines.

\section{DERIVATION OF THE THREE-ZONE MODEL}

A three-zone heat-release rate model for dual-fuel engines is now developed based on previously derived three-zone models for diesel engines $[14,15]$. After the start of injection the cylinder contents are divided into three zones:- zone 1 contains the liquid diesel that has been injected into the cylinder, zone 2 consists of the unburned charge air, or air and gaseous fuel, and once combustion begins a third zone (zone 3 ) of combustion products is formed. The concept of the model is shown in figure 2.

\section{$<$ Figure 2>}

\subsection{Governing Equations for the Zone Masses}

The total mass (m) in the combustion chamber (after inlet valve closure) is defined as the trapped air, residual exhaust gasses, and in the dual-fuel case, a gaseous fuel. This mass also includes the mass of fuel after the start of injection. The charge air and gaseous fuel proportions can be estimated from measured mass flow rates, but as the gas exchange process is not simulated, the residual gas fraction is assigned an arbitrary value and composition, following [2]. After the start of fuel injection, the mass of the cylinder also includes the mass of the diesel fuel. Therefore the conservation of mass in the cylinder at any instant can be expressed as

$$
m=m_{u}+m_{b}+m_{f}
$$

where $m_{u}$ is the mass of the unburned zone,

$\mathrm{m}_{\mathrm{b}}$ is the mass of the burned zone, and

$\mathrm{m}_{\mathrm{f}}$ is the mass of the diesel zone.

The difference between the mass of fuel injected $\left(\mathrm{m}_{\mathrm{fi}}\right)$ at any instant and the current mass in the fuel zone gives the rate at which fuel is consumed. Thus at any instant, the mass of diesel fuel that is burned $\left(\mathrm{m}_{\mathrm{fb}}\right)$ is 


$$
m_{f b}=m_{f i}-m_{f}
$$

It is assumed that unburned gasses are drawn into the burned zone in such a way that the oxygen content bears a stoichiometric relation to the mass of fuel burned. In the dual-fuel case there is the added complexity that the mass of the burned zone will also be a function of the mass of gaseous fuel that has been burned.

The accepted description of dual-fuel combustion [1,3] was deduced on the basis of heatrelease rate analysis where the combustion of the two fuels occurred in a fixed proportion, so this would be a reasonable starting point for this analysis. It is assumed that combustion occurs at a stoichiometric air-fuel ratio, $\mathrm{AFR}_{\mathrm{s}}$. The $\mathrm{AFR}_{\mathrm{s}}$ have two hydrocarbon fuel components with molecular formulas of $\mathrm{C}_{\mathrm{xd}} \mathrm{H}_{\mathrm{yd}}$ and $\mathrm{C}_{\mathrm{xg}} \mathrm{H}_{\mathrm{yg}}$; and the mass ratio of the two fuels is known [19]

$$
\begin{array}{r}
A F R_{S}=\frac{(\alpha(x d+y d / 4)+\beta(x g+y g / 4)) M W_{\text {air }}}{\alpha\left(x d M W_{C}+y d M W_{H}\right)+\beta\left(x g M W_{C}+y g M W_{H}\right)} \\
\alpha=\frac{m_{d}}{m_{d}+m_{g}} \text { and } \beta=\frac{m_{g}}{m_{d}+m_{g}}
\end{array}
$$

Where $m_{d}$ is the mass of diesel fuel, $m_{g}$ is the mass of the gaseous fuel and MW refers to the molecular weight. This definition of total $\mathrm{AFR}_{\mathrm{s}}$ accounts for the additional mass entrained into the burned zone due to the combustion of the gaseous fuel. The mass of fuel burned is solved as part of the final equation set and is therefore known. Thus, the mass conservation equation (5) is now given by

$$
m=m_{u}+m_{f}+\left(m_{f i}-m_{f}\right)\left(1+A F R_{S, t o t}\right)+\left(m_{f i}-m_{f}\right)\left(\frac{\beta}{\alpha}\right)\left(1+A F R_{S, t o t}\right)
$$

\subsection{Governing Equations for Zone Volumes}

At any instant, the volume of the combustion chamber contents is given by the sum of the volumes of each zone. The gas constant for each zone is calculated through knowledge of the composition of mole fractions of the species in that zone. It is assumed to be constant for the fuel and unburned zones, but can vary for the burned zone. The variation with temperature is only significant when temperatures are high enough for dissociation to occur; however the temperatures of the unburned and fuel zones do not reach these levels. 


$$
\begin{aligned}
p V=m_{u} R_{u} T_{u}+ & m_{f} R_{f} T_{f} \\
& \left\{\left(m_{f i}-m_{f}\right)\left(1+A F R_{S, t o t}\right)+\left(m_{f i}-m_{f}\right)\left(\frac{\beta}{\alpha}\right)\left(1+A F R_{S, t o t}\right)\right\} R_{b} T_{b}
\end{aligned}
$$

where $\mathrm{p}$ is pressure $\left(\mathrm{N} \cdot \mathrm{m}^{-2}\right)$,

$\mathrm{V}$ is volume $\left(\mathrm{m}^{3}\right)$,

$\mathrm{R}$ is the gas constant $\left(\mathrm{J}^{\mathrm{kg}} \mathrm{kg}^{-1} \cdot \mathrm{K}^{-1}\right)$, and

$\mathrm{T}$ is temperature $(\mathrm{K})$.

The subscripts $\mathrm{u}, \mathrm{b}$ and $\mathrm{f}$ refer to the unburned, burned and diesel fuel zones respectively

\subsection{Governing Energy Equations}

For the unburned zone, the relationship between internal energy and enthalpy can be expressed as,

$$
d U_{u}=d m_{u}+C_{p u} d T_{u}-d p V_{u}-p d V_{u}
$$

where $\mathrm{U}$ is the internal energy $\left(\mathrm{J}_{\mathrm{kg}}{ }^{-1}\right)$,

$\mathrm{h}$ is the enthalpy $\left(\mathrm{J}_{\mathrm{kg}}{ }^{-1}\right)$, and

$\mathrm{C}_{\mathrm{p}}$ is specific heat at constant pressure $\left(\mathrm{J} \cdot \mathrm{kg}^{-1} \cdot \mathrm{K}^{-1}\right)$.

Substituting this relationship into the first law then gives the instantaneous rate of heat addition to the unburned zone

$$
\frac{d T_{u}}{d \theta}=\frac{d p}{d \theta} \frac{R_{u} T_{u}}{p c_{p u}}+\frac{d Q_{u}}{m_{u} c_{p u}}
$$

where $\mathrm{Q}$ is the heat transfer, and

$\theta$ is crank angle (degrees).

The First Law of Thermodynamics for the fuel zone can be written as;

$$
d Q_{f}+d m_{f i}\left(1 / 2 v_{i n j}^{2}\right)=d m_{f} h_{f}+p d V_{f}+d U_{f}
$$

where $v_{\text {inj }}$ is injection velocity $\left(\mathrm{m} \cdot \mathrm{s}^{-1}\right)$. 
Following the same procedure as for the unburned zone, the rate of heat addition to the fuel zone is

$$
\frac{d T_{f}}{d \theta}=\frac{d p}{d \theta} \frac{R_{f} T_{f}}{p c_{p f}}+\frac{d m_{f} / d \theta\left(1 / 2 V_{i n j}^{2}\right) d Q_{f} / d \theta}{m_{f} c_{p f}}
$$

\section{$2.4 \quad$ Overall Energy Balance}

The First Law of Thermodynamics applied to all three-zones can be expressed as,

$$
\frac{d Q_{T}}{d \theta}+\frac{d m_{f i}}{d \theta}\left(h_{f}+1 / 2 V_{i n j}^{2}\right)=p \frac{d V}{d \theta}+\frac{d U}{d \theta}
$$

Which can be integrated (between inlet valve closure and exhaust valve opening) to give

$$
Q_{T}+m_{f i}\left(h_{f}+1 / 2 V_{i n j}^{2}\right)=W+\left(m_{u} u_{u}+m_{f} u_{f}+m_{b} u_{b}\right)-U_{0}
$$

where $W=\int_{\theta_{0}}^{\theta} p d V, \mathrm{Q}_{\mathrm{T}}$ is the cumulative amount of heat transferred during the same interval and the subscript ${ }_{\mathrm{o}}$ identifies the initial condition.

Replacing the mass of the burned zone, gives the final equation,

$$
\begin{aligned}
Q_{T}+m_{f i}\left(h_{f}+1 / 2\right. & \left.V_{i n j}^{2}\right)=W+m_{u} u_{u}+m_{f} u_{f} \\
& +\left\{\left(m_{f i}-m_{f}\right)\left(1+A F R_{S, t o t}\right)+\left(m_{f i}-m_{f}\right)\left(\frac{\beta}{\alpha}\right)\left(1+A F R_{S, t o t}\right)\right\} u_{b}-U_{0}
\end{aligned}
$$

\subsection{Implementation of the Model}

The above system can be reduced to two ordinary differential equations (equations 7 and 9) and three algebraic equations with five unknowns (equations 4, 5 and 12). The differential equations are solved by means of a 4th Order Runge-Kutta method [16,17] then the algebraic equations can be solved by means of a Newton-Rhapson technique [18].

The model was implemented using FORTRAN 77, and a flow diagram of this is shown in figure 3. The program first calculates the mixture properties and heat-transfer rates in the unburned zone from inlet valve closure to start of injection using the initial conditions, pressure data and the ideal gas law. This gives values for internal energy $\left(\mathrm{U}_{0}\right)$, compression work $\left(\mathrm{W}_{0}\right)$ and initial heat transfer during compression $\left(\mathrm{Q}_{0}\right)$ at the reference instant of inlet 
valve closure. The fuel zone appears just after the start of injection, and the burned zone appears at the start of combustion where upon the equations derived for the three-zone model are solved. A record of the burned zone composition is preserved and used to calculate the new thermodynamic properties. The outputs from the model are net and cumulative heatrelease rates, the temperatures of each zone and the mass fraction burned.

\section{$<$ Figure 3>}

\subsection{Additional Variables}

Before the preceding equation set can be solved, expressions are required for rates of change in cylinder pressure and engine geometry (available in standard texts [2,6,17], thermodynamic gas properties (using the method described by Olikara and Borman [19], heat transfer (using the Annand [20], correlation) and finally, fuel injection profiles.

Calculation of fuel injection rate was made via the experimentally recorded fuel consumption data leading to a known total mass injected per cylinder [21]. Needle lift data were used to calculate injection duration and the proportion of the total mass of fuel injected in each calculation step were obtained from the fuel line pressure data. Using this data, the mass of fuel injected in each recorded interval was found by

$$
\dot{m}_{f}=C_{D} A \sqrt{(2 \Delta P / \rho)}
$$

$\mathrm{C}_{\mathrm{D}}$ is the discharge coefficient and was taken to be 0.7 , while $\mathrm{A}$ is the nozzle area and $\Delta \mathrm{P}$ is the different between cylinder pressure and injection pressure. This yields a known injection pressure which is then used to calculate injection velocity by a simplified form of Bernoulli's equation [21]

$$
V_{e f f}=C_{D} \sqrt{(2 \Delta P / \rho)}
$$

where $\mathrm{V}_{\mathrm{eff}}$ is the injection velocity $\left(\mathrm{m} . \mathrm{s}^{-1}\right)$.

The total mass of fuel injected at any crank angle position is then obtained by numerical integration of the instantaneous mass flow rate using a trapezoidal rule algorithm. Finally, the start of injection is found from as the point at which need injector needle has lifted to 10 $\%$ of its maximum value. The end of injection is found in a similar way [17]. 


\section{EXPERIMENTAL PROGRAM}

\subsection{Test Facility}

The engine used in this study is often found in small diesel-genset applications between 20 and $60 \mathrm{kVA}[22]$. The typical duty cycle of this type of engine is to operate between $25 \%$ and $75 \%$ load for $90 \%$ of its running time. Therefore, engine performance data were obtained under steady-state operating conditions at $1500 \mathrm{rpm}$ (synchronous speed). Two test cases are examined at $3 / 4$ load, (as this condition showed the greatest variation in mass burning rate patterns) and $1 / 4$ load (the most consistently stable operating point). For each load, the minimum and maximum methane substitution levels are examined where the contribution of methane to total energy release was $10.5 \%$ and $82.0 \%$ respectively. Table 1 lists the engine specifications.

\section{$<$ Table 1 $>$}

The engine was coupled to a Heenan-Dynamatic MkII 220kW eddy current dynamometer, which controlled and measured torque and speed with maximum error of $+/-1 \mathrm{rpm}$ and $+/-2$ $\mathrm{Nm}$ respectively. Intake airflow was measured using a laminar viscous-flow air meter with a type 5 Cussons manometer. Various temperatures around the engine were measured with ' $\mathrm{K}$ type' thermocouples and diesel fuel consumption was recorded using a volumetric fuel measurement system. The installation is shown schematically in figure 4.

\section{$<$ Figure 4 $>$}

High-speed data (cylinder pressure, fuel line pressure and crank angle) were acquired using a National Instruments PCIO-MX16-E PC-BNC rack interface coupled with a BNC 2090 capture board. Cylinder pressure was measured using a Kistler type 6053B60 piezocapacitive transducer connected to a Type 5011 charge amplifier. Fuel line pressure was obtained using a Kistler 4065A piezo-resistive sensor and 4617A amplifier. This data was recorded at a resolution of 0.5 degrees crank angle on the falling edge of the crank degree marker signal from an AVL optical encoder, mounted directly on the engine crankshaft. 


\subsection{Dual-fuel Conversion}

The most straight forward and inexpensive method of admitting a gaseous fuel to the dualfuel engine is a simple central-point mixing system [23]. To this end, a venturi-type gas mixer valve was installed at a distance of ten pipe diameters upstream of the inlet manifold to ensure the complete mixing of the air and gaseous fuel was achieved prior to their induction to the combustion chamber [19]. Gaseous fuel flow-rate was controlled by a needle valve located immediately upstream of an Omega FMA 1610 mass flow meter, which also recorded line pressure and gas temperature. The details of this supply system, for methane in this work, are shown schematically in figure 5.

\section{$<$ Figure 5 $>$}

The only other modification to the engine was the replacement of standard injectors with reduced flow injectors. Previous experimental work [22], conducted using two sets of injectors for this engine (identified as 'standard' and 'low-flow'), demonstrated that the reduced size of the nozzle holes on the low-flow injector resulted in improved fuel atomisation, reduced penetration length and thus that the diesel fuel spray is less likely to impinge on the combustion chamber walls [23].

\section{RESULTS AND DISCISSION}

\subsection{Comparison with a Single-zone Model}

In order to establish whether the three-zone technique represents an improvement over singlezone techniques, the model derived above is compared with a single zone model [2], described in equation 15 (where $\gamma$ is the ratio of specific heats).

$$
d Q_{\text {comb }}=\left(1+\frac{1}{\gamma-1}\right) P d V+\left(\frac{1}{\gamma-1}\right) V d P+d Q_{w}
$$

The results from both models are compared for the diesel case, and presented in figure 6 . The single-zone model shows slightly higher initial rates of heat-release leading to a slightly higher premixed peak. The different initial rates of heat-release predicted by the single-zone model can be attributed to the assumption of fixed values of $\gamma$, which takes a value of 1.35 during compression, then switches (at top dead centre, TDC) to a value of 1.3 during combustion. The reliance on constant specific heat values is unrealistic and known to be a problem in single-zone models $[2,6]$. The switch from 1.35 to 1.3 at TDC distorts the single- 
zone calculation of initial heat-release rates causing the 'hump' shown in figure 6 . Where the value of $\gamma$ is high (before TDC), the heat-release rates will be too low, and where the value of $\gamma$ is low (after TDC), the predicted heat-release rates will be to high.

\section{$<$ Figure 6 $>$}

The differences between the single- and three-zone models become more pronounced during the diffusion- and late-burning periods. Here the three-zone model shows much extended combustion durations (by 7 degrees crank angle), and higher rates of heat-release during diffusion burning. The lower rates of diffusion heat-release for the single-zone model are due to the assigned value for $\gamma$. This would imply that the three-zone model, which avoids the assumption of a fixed $\gamma$ value, yields the more reliable results. The most likely cause of the extended combustion duration is the heat transfer model, which has an increasingly reduced effect with time for the three-zone model (it is assumed that only the unburned zone is in contact with the cylinder walls).

The issue with fixed $\gamma$ values has been refined in most modern single-zone models for diesel heat-release rate analysis, but this is not so for dual-fuel investigations. The accepted description of the dual-fuel combustion process, (see above), rests on the model used by Khan [10], which used two different and fixed values of $\gamma$ during compression and combustion. In order to investigate the effects of using this fixed value, the calculated heatrelease rates from a single-zone [10] are compared to the three-zone model.

In this work, two gaseous fuelling levels were compared. A low methane fuelling level of 10 $\%$ (by energy replacement) was compared with a high methane level of $82 \%$, (these being the lower and upper limits of methane fuelling level that could be achieved in this conversion method whilst maintaining stable engine operation, i.e. a combustion process that was free from misfire or knock). The comparison of net heat-release rates for these two methane substitution levels at $1 / 4$ load in figure $7 \mathrm{a}$ (for the low methane fuelling level) and figure $7 \mathrm{~b}$ (for the high methane fuelling level) shows that the single-zone model predicts initially slow rates of heat-release until TDC, lower rates of heat-release overall, and shorter combustion durations than the three-zone model. At TDC, a sudden increase in rates of heat-release occurs, and the location of this almost step-change coincides with the change in values of $\gamma$. By comparison, the three-zone model shows a steady increase in heat-release without this ‘step' change. 


\section{$<$ Figures $7 \mathbf{a}$ and $7 \mathbf{b}>$}

According to the accepted description, where dual-fuel combustion proceeds in three stages, the first stage is due to the combustion of approximately half of the pilot and any gaseous fuel that is entrained by it. This stage should narrow as less pilot fuel is used $[1,3]$. The results in figure $7 \mathrm{a}$ actually show a more delayed combustion event where the step change in $\gamma$ is hidden because the start of combustion coincides with TDC. The second stage of combustion is supposed to be due to combustion of the remaining pilot fuel, and as cylinder temperature increases, stage I and II should become indistinct. The three-zone model results show that the overlap of stage I and II is in fact a function of start of combustion relative to the change in $\gamma$ values. The transition from stage I and II is an artefact induced by Khan's model.

A different issue can be identified in figure $7 \mathrm{~b}$ at the end of the combustion stage, where negative heat-release rates are observed. Gatowski [24] suggested that this is due to inaccurate pressure data at the end of the stroke due to the thermal expansion of the pressure transducer (which factor was minimised in this study $[25,26]$ ), or deficiencies in the thermodynamic combustion model. As the three-zone model employs an equilibrium combustion model [19], the negative heat-release rates are much delayed compared with the single-zone model, and in this respect the three-zone model represents an improvement. However, these negative heat-release rates do ultimately occur, and this is because heat transfer effects between the three-zones were neglected. The omission of zone-to-zone heat transfer causes predictions of burned zone temperature to be too high, and this results in the three-zone model's under-prediction the heat transfer beyond 25 degrees CA ATDC.

\subsection{Investigation of Fuelling Assumptions}

The three-stage description of combustion has become a corner stone of subsequent dual-fuel research, and a significant proportion of research $[1,3,11,13,23]$ rests upon that argument. Many combustion models employ the corresponding Weibe functions or a modified Whitehouse and Way [12] method. However, it was established in section 4.1 that part of Karim's description is based on a modelling artefact induced through a switch in $\gamma$ values. If Karim's three-stage description is discounted, the 'equivalent-fuel' description remains as the only practical alternative that has been used in dual-fuel research.

The physical processes of the pilot fuel cannot change, even when a second fuel is present in the combustion chamber. The diesel fuel jet must mix with air to form a (near to) 
stoichiometric AFR in order for ignition to take place, and this mixing with air must continue while the diesel fuel is burned. Consider one element of diesel fuel; this element cannot ignite until it has mixed with sufficient air. In the dual-fuel case, the air that is entrained to the pilot spray also contains a gaseous fuel, so the mixing process is likely to take longer before an ignitable AFR is achieved, and every element of the pilot fuel will combust in conjunction with a portion of the gaseous fuel. Therefore, the diesel fuel is not able to preferentially extract sufficient oxygen from the gaseous fuel-air mixture ahead of the gaseous fuel, nor is the diesel fuel able to burn at a richer fuel-air ratio just because the gaseous fuel has reserved some proportion of the oxygen for its own combustion reaction [26]. For this reason, the idea of an equivalent-fuel was first proposed by Khan [10] who, in the course of his experimental work, calculated the rate of heat-release $(\mathrm{dQ} / \mathrm{dt})$ as

$$
\frac{d Q}{d t}=\frac{1}{J(\gamma-1)}\left[\gamma P \frac{d v}{d \theta}+V \frac{d P}{d \theta}\right] \frac{d \theta}{d t}
$$

where $\theta$ is crank angle and $t$ is time. The proportion of heat-released due to each fuel was determined at the start of the calculation from their measured proportions, and expressed in equation 16 through the term $\mathrm{J}$. This term combines both fuels on the basis of their molecular formulae into an equivalent-fuel comprising of the same total number of carbon and hydrogen atoms.

The definition of an equivalent-fuel requires that the primary and pilot fuels are assumed to burn in the same fixed proportions as they were admitted to the engine throughout the whole combustion at an overall stoichiometric ratio to air. However, the relative proportions of pilot and primary fuel that burn together will be a function of the in-cylinder mixing processes, regardless of the fuel quantities supplied to the engine, thus the actual combustion process could be richer, or leaner than the fuel supplies would suggest. In order to investigate this effect, the equivalence ratio was varied for the equivalent-fuel for the calculation of burned gas properties. The results are more pronounced for the $82 \%$ methane substitution level so this data are presented in figures $8 \mathrm{a}$ and $8 \mathrm{~b}$.

When leaner equivalence ratios $(\Phi)$ are used (figure $8 \mathrm{a}$ ) or when richer equivalence ratios are used (figure $8 \mathrm{~b}$ ), the mass-burning rates are increased. This is expected as the most fuel efficient combustion occurs at a stoichiometric AFR, which would require the least mass of fuel to be burned in each crank angle to yield the observed pressure rise. If stoichiometric 
combustion is assumed, and actual combustion occurs at a rich equivalence ratio (figure $8 \mathrm{~b}$ ), the error in the mass burned will be smaller than that observed if actual combustion occurs at a lean equivalence ratio. In either case, values of mass burning rate converge during late combustion, the position of the premixed peak is not altered, and the combustion duration is unchanged. For the $82 \%$ gas case the maximum error in mass burning rate for the extreme case of $\Phi=0.6$ was $53.6 \%$ compared with an error of $6.4 \%$ at the opposite extreme of $\Phi=$ 1.4. For the $10 \%$ gas case, the maximum errors were $46.9 \%$ when $\Phi=0.6$ and $6.1 \%$ when $\Phi=0.6$. The maximum error occurs at the premixed peak.

Where a three-stage combustion process is assumed, the combustion process first involves mostly diesel, then mostly the gaseous fuel. The consequences of this assumption are examined by using the three-zone model to test a baseline case using the equivalent-fuel method against an assumption that the same combustion process involved either diesel or methane alone. The results for the $82 \%$ methane substitution level are shown in figure 9 .

\section{$<$ Figure 9 $>$}

The assumption that energy release is due only to the combustion of the diesel fuel results in a higher rate of mass burning, which is unsurprising as the diesel fuel makes a much higher contribution to heat-release due to its higher (than methane) energy content. The assumption that combustion is due to the gaseous fuel alone causes an under-prediction of mass-burning rate. The diesel only assumption yields a maximum error of $2.15 \%$, while the methane assumption gives a maximum error is $-5.15 \%$. These errors occur at the premixed peak and decrease to zero during the remaining combustion process. This shows that if the equivalentfuel assumption is correct, but a three-stage combustion pattern has been used in a modelling study, initial rates of heat-release will be over-estimated while later stages of heat-release will be under-estimated - the two effects tend to balance out so that combustion duration remains unchanged.

In simple terms, heat-release rate analysis reveals how much fuel must burn in each time-step to result in the observed pressure change. This is a straightforward matter when a single fuel is involved. When two fuels are used, heat-release rate analysis cannot identify the relative proportions of the two fuels that burn during each time step. What can be said is that if the early combustion process involves mostly the pilot fuel and the later stages involve mostly the primary fuel, heat-release rate models will under-predict the initial quantity of diesel consumed and over-predict the amount of gaseous fuel consumed [26]. If the two fuels burn 
together in each time-step, when the fuels burn at lean equivalence ratios, heat-release rate models will over-predict the amount of fuel consumed, and when the fuels burn at rich equivalence ratios, heat-release rate models will under-predict the fuel that is consumed.

\section{$5 \quad$ CONCLUSIONS}

The description of diesel combustion proceeding through four sequential stages does not mean that the combustion process itself changes. However, the description of dual-fuel combustion as proceeding in three stages has resulted in the interpretation that the combustions process does change. Even without the benefit of any further analysis, the idea that two fuels experience entirely distinct combustion mechanisms within the same system, and at the same time, appears to be highly implausible.

A three-zone heat-release rate technique has been proposed for the analysis of dual-fuel combustion processes. When used for diesel analysis, the model shows slightly lower, later initial rates of heat-release and a slightly lower premixed peak compared with single-zone techniques. The differences are larger during the diffusion and late burning period where the three-zone model shows extended combustion durations and higher rates of heat-release during diffusion burning. When applied to the dual-fuel combustion process, the analysis suggests that the traditional three-stage description of dual-fuel combustion is based upon a modelling artefact. What appears as stages I and II are actually caused by the switch between gamma values simulating compression and combustion in the original dual-fuel heat-release rate analysis. When the concentration of the gaseous fuel is increased, stage I and II do not merge - rather the start of combustion is delayed and the effect of the switch in gamma values is masked because it occurs closer to the real start of combustion point.

Perhaps then, it is better to think of a dual-fuel combustion process primarily as a diesel combustion process, where the diesel injection undergoes an ignition delay, and premixed phase, a diffusion burning phase and a late burning phase. In this case the effect of the second fuel is the widening of the reaction zone around each igniting element of the pilot fuel. The physical processes of combustion will remain unchanged, but the chemical reaction will involve different quantities of oxygen in each stage.

Heat-release rate analysis is unable to shed any light on this alternative description. The determination of the actual combustion mechanisms of the two fuels are beyond the scope of a three-zone heat-release rate model and must, of course, be established by further modelling 
and experimental programs. However, it is noted that the three-zone technique represents a significant improvement for dual-fuel analysis than a single-zone technique, as it is conceptually closer to the reality of dual-fuel combustion, it avoids assumed values of $\gamma$, and it minimises the effects of negative heat-release rates towards the end of the combustion process.

$<$ Notation $>$ 


\section{REFERENCES}

1. Karim, G.A. The Dual Fuel Engine of the Compression Ignition Type - Prospects, Problems and Solutions - A Review. SAE transactions, 1983, 92(33), 3.569 - 3.577.

2. Heywood, J.B. Internal Combustion Engine Fundamentals $2^{\text {nd }}$ ed. eds. A. Duffy and J.M. Morris, 1988, McGraw-Hill.

3. Karim, G.A. Combustion in Gas Fuelled Compression-Ignition Engines of the Dual Fuel Type. Journal of Engineering for and Gas Turbines and Power, 2003, 125(3) 827-837.

4. Papagiannakis, R.G. and Hountalas, D.T. Experimental investigation concerning the effect of natural gas percentage on performance and emissions of a DI dual fuel diesel engine. Applied Thermal Engineering, 2003, 23, 353-365.

5. Bruntt, M.F.J. and Platts, K.C. Calculation of Heat-release in Direct Injection Diesel Engines. SAE transactions, 1999, 108(3), 161-175.

6. Ferguson, C.R. and Kirkpatrick, A.T. Internal Combustion Engines: Applied Thermodynamics. 2nd ed, ed. J. Hayton. 2001, John Wiley \& Sons, Inc

7. Watson, N. and Janota, M.S. Turbocharging the Internal Combustion Engine. 1982, MacMillan Press Ltd, London.

8. Egnell, R. Combustion Diagnostics by Means of Multi Zone Heat-release Analysis and NO Calculation. SAE transactions, 1998, 107(44), 691-710.

9. Catania, A.E., Misui,D., Mittica, A. and Spessa, E. A Refined Two-Zone Heatrelease Model for Combustion Analysis in SI Engines. JSME International Journal - Series $B, 2003,46$ (1), 75-85.

10. Khan, M.O. Dual-Fuel Combustion Phenomena, in Department of Mechanical Engineering. 1969, Doctoral Thesis, Imperial College of Science and Technology, London.

11. Pirouzpanah, V. and Amiraslani, K. A model to predict performance and heatrelease of dual-fuel diesel engines. In Symposium on Gas Engines and Co-Generation, Solihul, 1990, (MEP). 
12. Whitehouse, N.D. and Way, R.J.B. A Simple Method for the Calculation of Heatrelease Rates in Diesel Engines Based on the Fuel Injection Rate. SAE paper number 710134, 1971.

13. Kishnan, S.R., Biruduganti, M., Mo, Y., Bell, S.R. and Midkiff, K.C. Performance and Heat-release Analysis of a Pilot-Ignited Natural Gas Engine. International Journal of Engine Research, 2002, 3(3), 171-184.

14. Sastry, G.V.J. and Chandra, H. A Three-Zone Heat-release Model for DI Diesel Engines. In International Congress \& Exposition, Detroit, February 1994, (SAE paper 940671).

15. Timoney, D.J., McNally, C.P. and Doyle, C.T. A Three-Zone Heat-release Model for Direct Injection Diesel Engines. In Theisel, Valencia, September 2000, pp 423-433.

16. Stroud, K.A. Further Engineering Mathematics. 3rd ed. 1996, MacMillan Press Ltd, London.

17. Stone, R. Introduction to Internal Combustion Engines. 3rd ed. 1999, Macmillan Press Ltd.

18. Press, W.H., Flannery, B., Teukolsky, S.A. and Vetterling, W.T. Numerical Recipes in Fortran 77: The Art of Scientific Computing. 2nd ed. 1992, Cambridge University Press.

19. Olikara, C. and Borman, G.L. A Computer Program for Calculating Properties of Equilibrium Combustion with Some Applications to I.C. Engines. SAE paper number, $750468,1975$.

20. Annand, W.J.D. Heat Transfer in the Cylinders of Reciprocating Internal Combustion Engines. Proceedings of the Institute of Mechanical Engineers, 1963, 177(36), 973-990.

21. Munson, B.R., Young, D.F. and Okiishi, T.H. Fundamentals of Fluid Mechanics. 3rd ed. 1998, John Wiley \& Sons, Inc, New York.

22. Patterson, J., Clarke, A. and Chen, R. Experimental Study of the Performance and Emissions Characteristics of a Small Diesel Genset Operating in Dual-Fuel Mode with Three 
Different Primary Fuels. Proceedings of the Institution of Mechanical Engineers, Part D, 221(8), 943-956.

23. Liu, Z. and Karim, G.A. Simulation of combustion processes in gas-fuelled diesel engines. Proceedings of the Institute of Mechanical Engineers, 1997, 211(A), 159-169.

24. Gatowski, J.A., Smith, M.K. and Alkidas, A.C. An Experimental investigation of Surface Thermometry and Heat-Flux. Experimental Thermal and Fluid Science, 1989, 2(3), 280-292.

25. Mbarawa, M., Milton, B.E. and Casey, R.T. An investigation of the effects of diesel pilot injection parameters on natural gas combustion under diesel conditions. Journal of the Institute of Energy, 2001, September 2001(74), 81-90.

26. Stewart, J. Combustion Diagnostics of a Dual Fuel Engine: An Experimental and Theoretical Study, 2006, Doctoral Thesis, Loughborough University. 


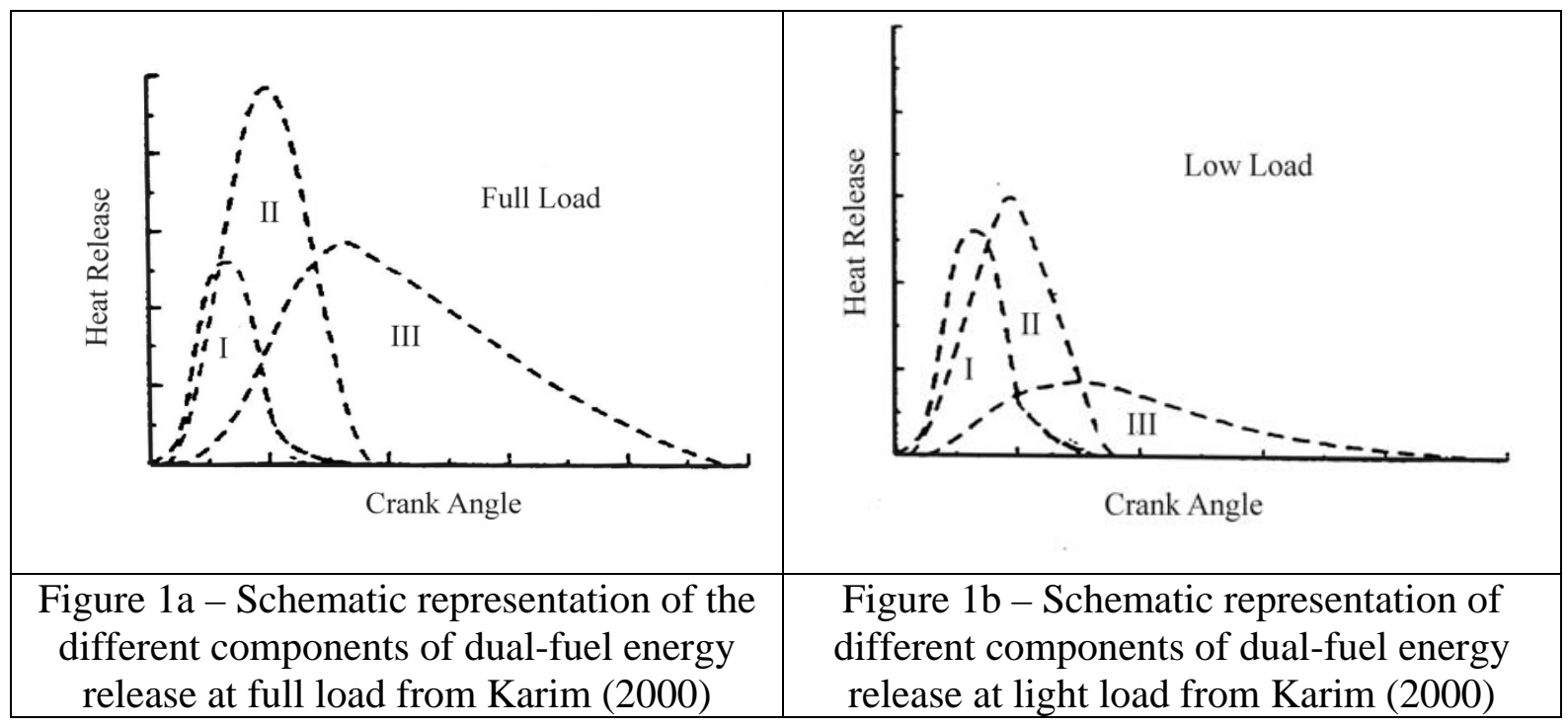




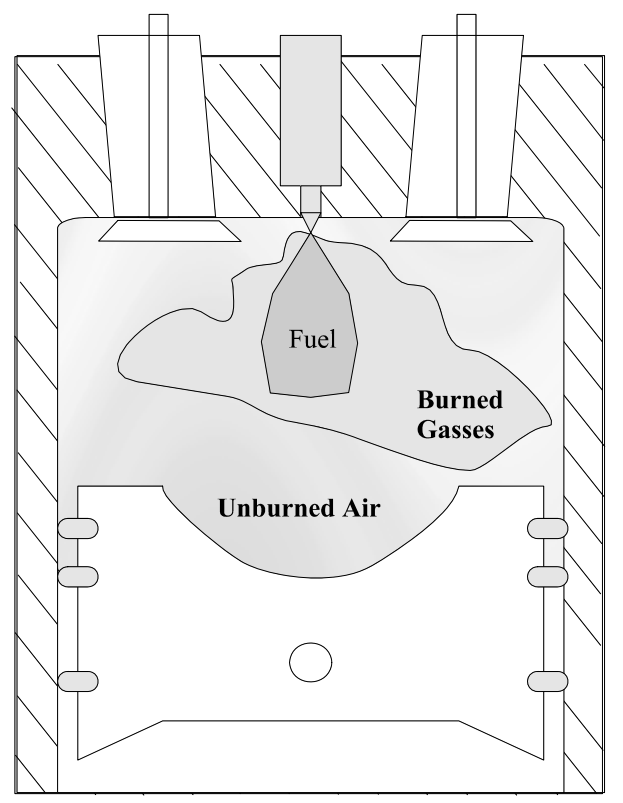

Figure 2 - Schematic representation of the three-zone model 
Figure 3 - Flow chart of the computer program

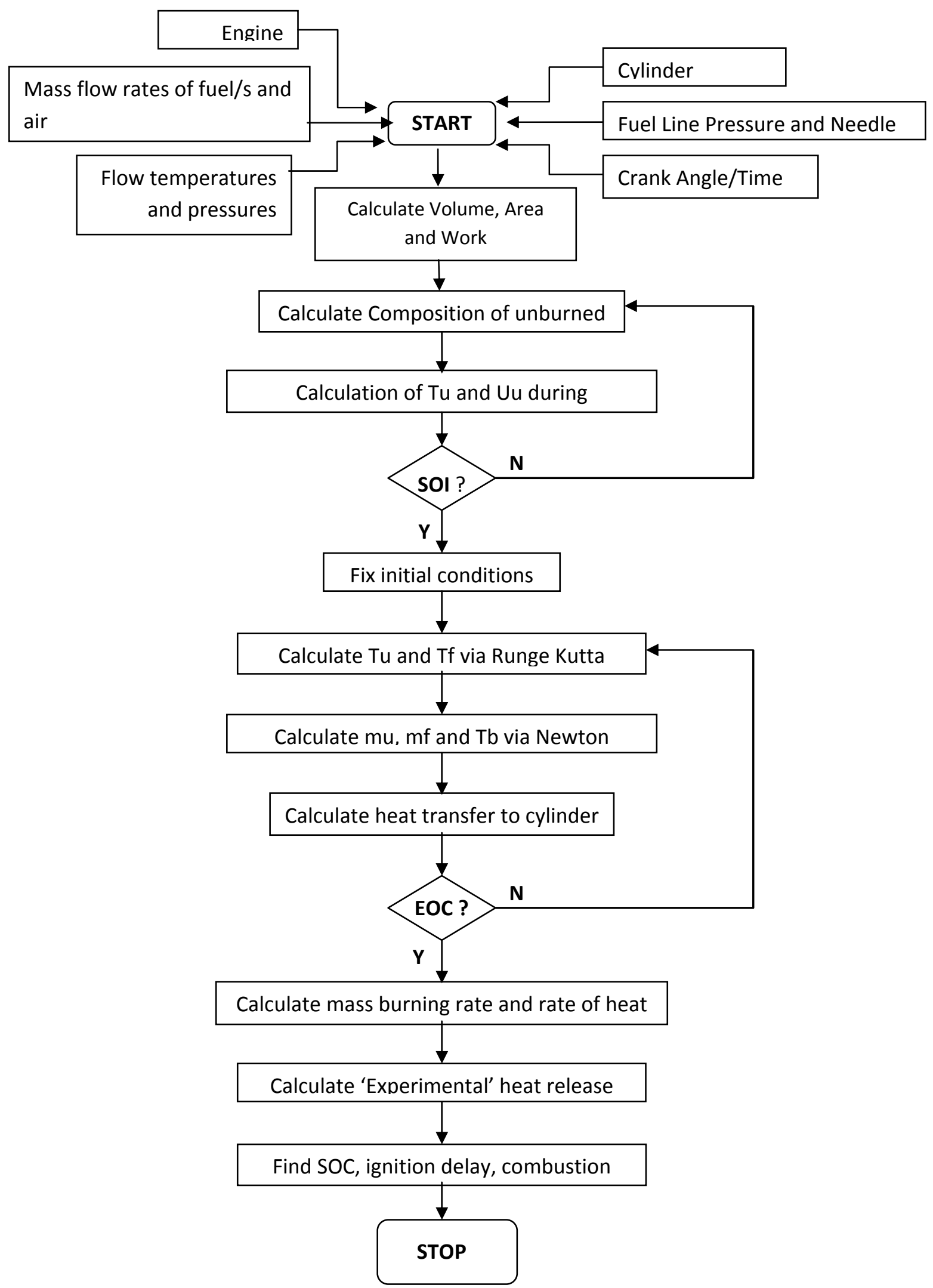




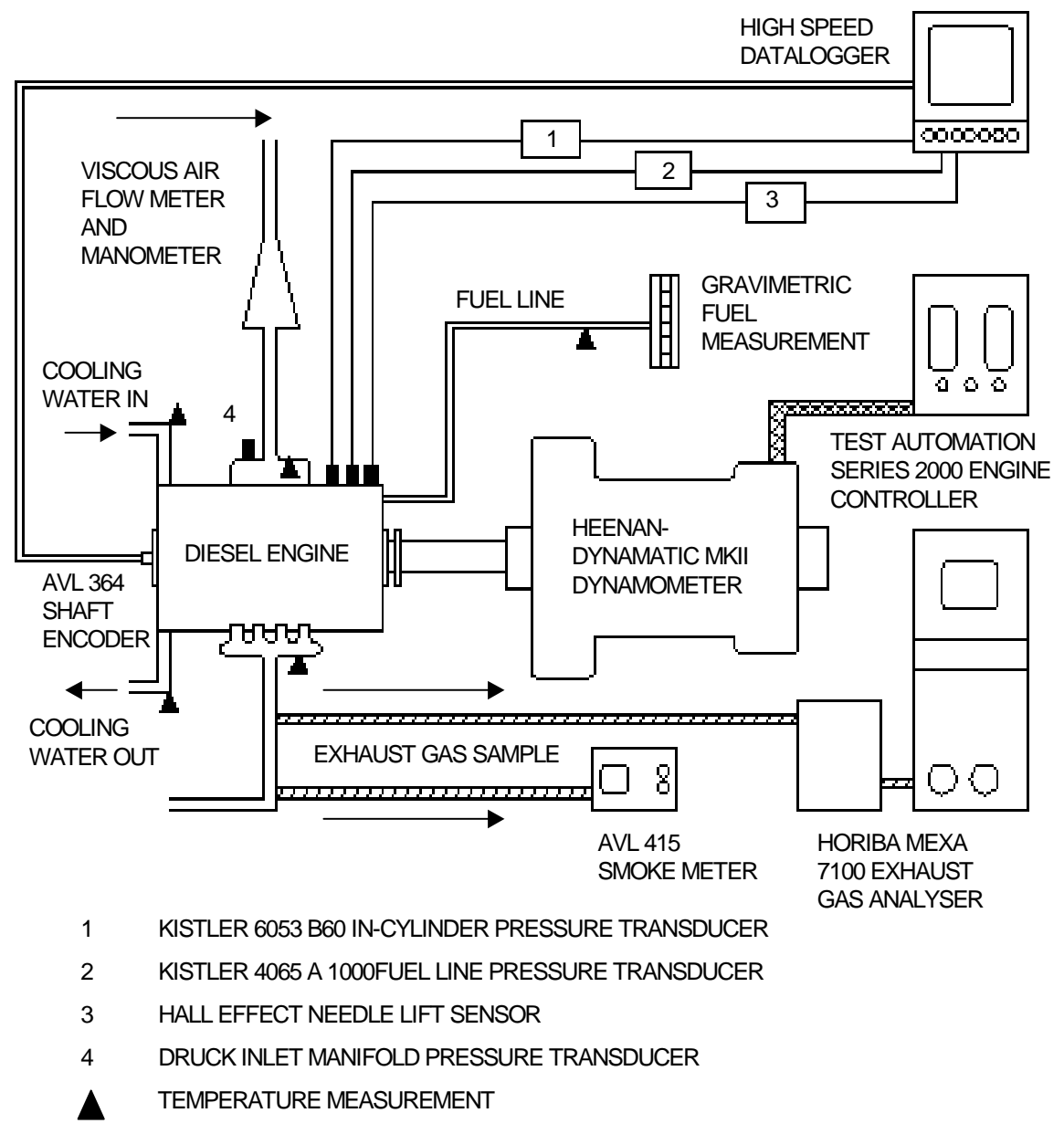

Figure 4 - Schematic diagram of the test engine and equipment 


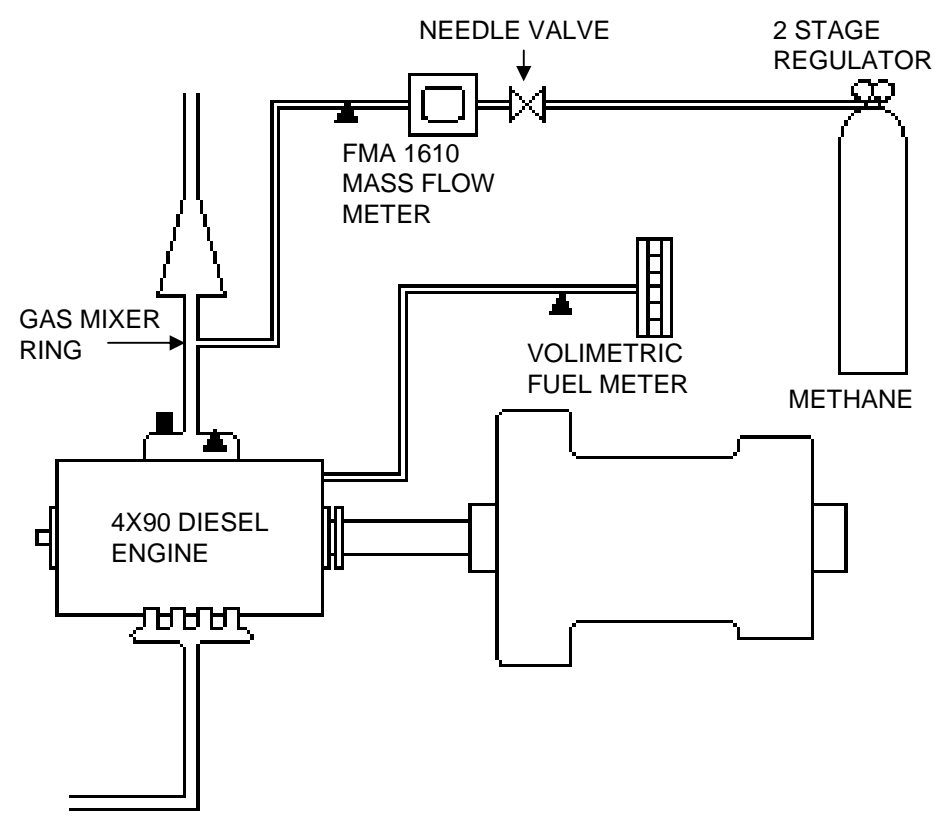

Figure 5 - Schematic diagram of dual-fuel installation 


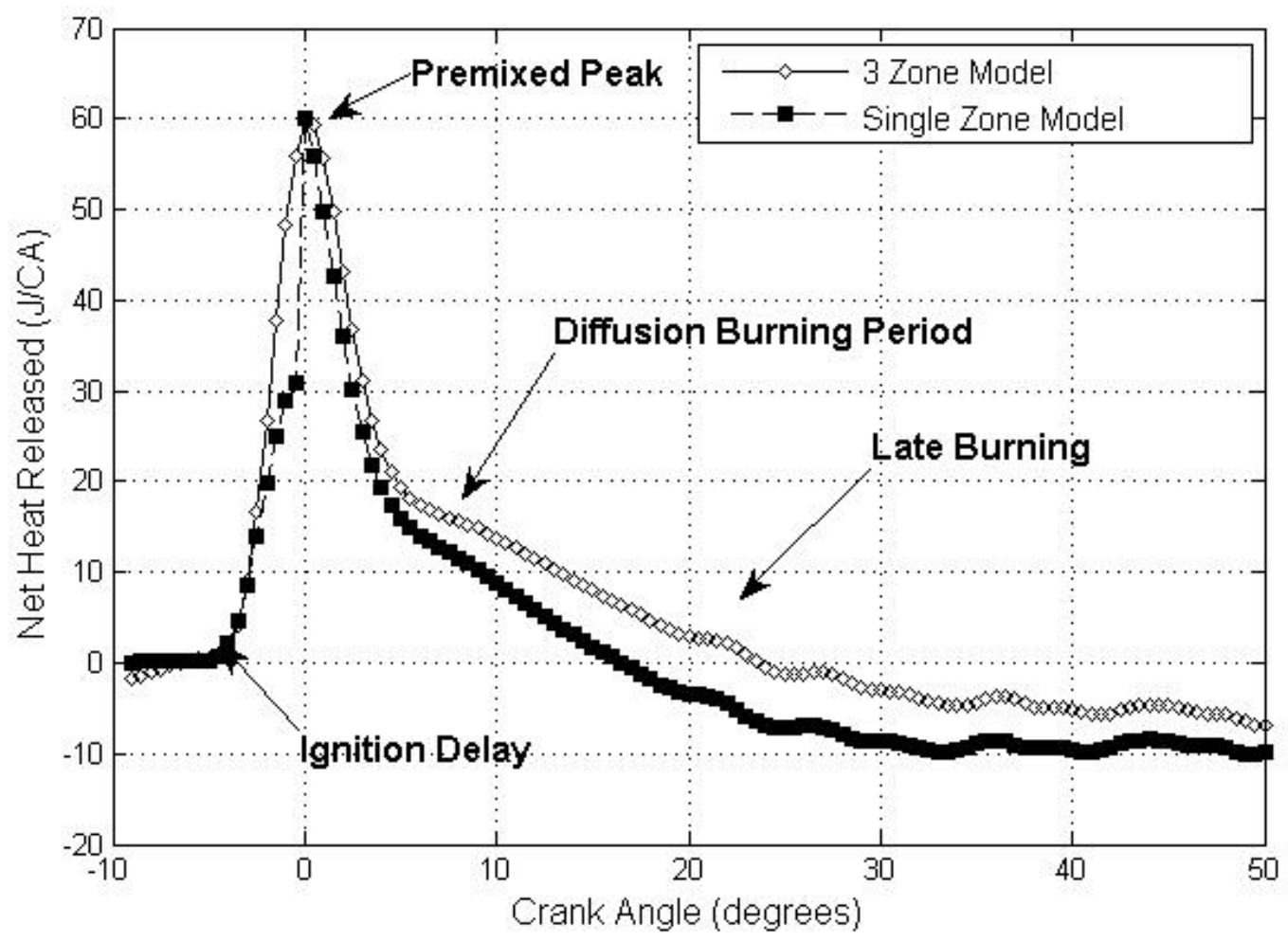

Figure 6 - Comparison of 3-Zone and Experimental Net Heat-Release Rate at $1 / 4$ Load for Diesel 


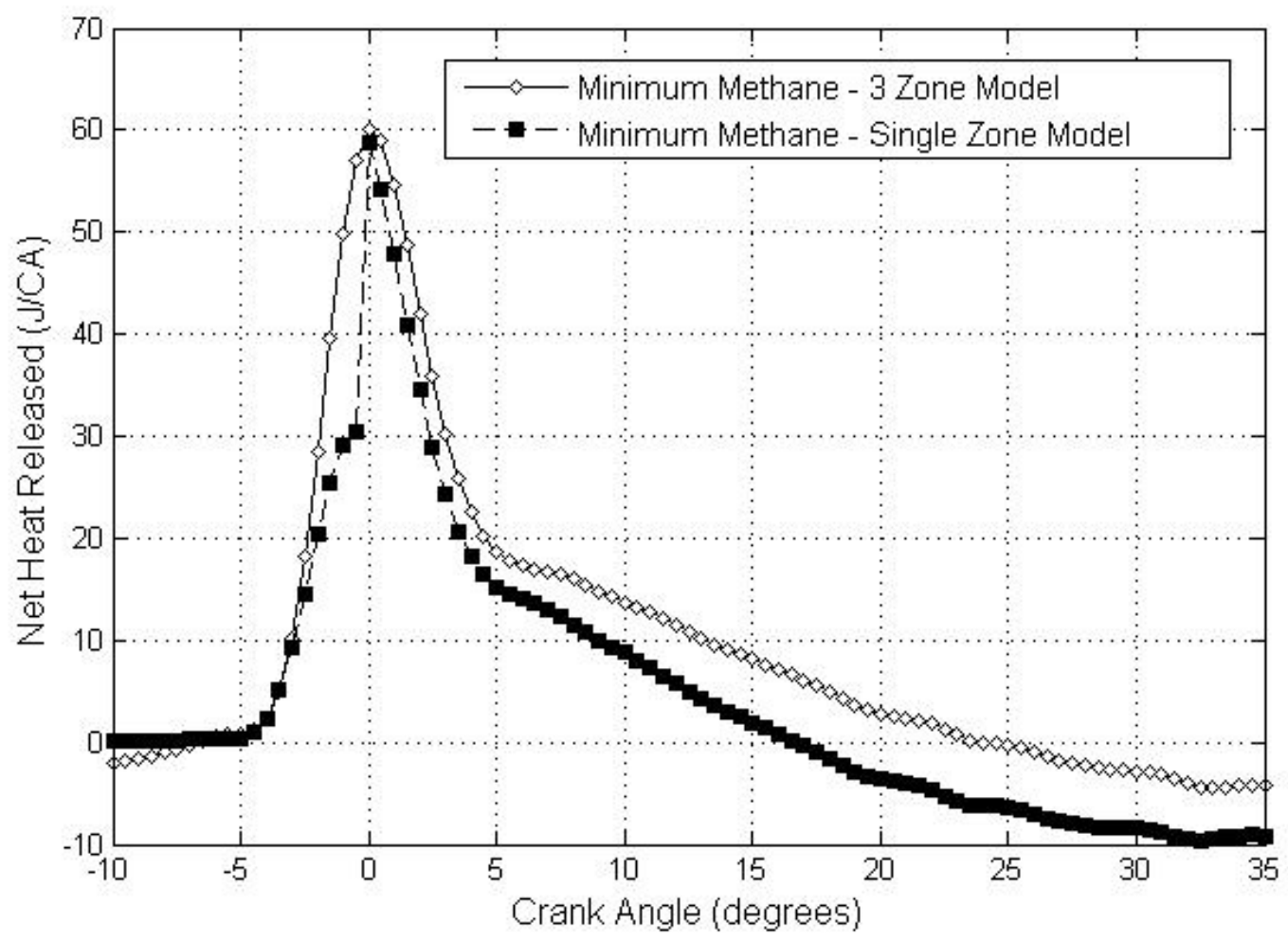

Figure 7a - Comparison of the 3-Zone and Experimental Net Heat-Release Rate at 1/4 Load for the Minimum Methane Fuelling Rate 


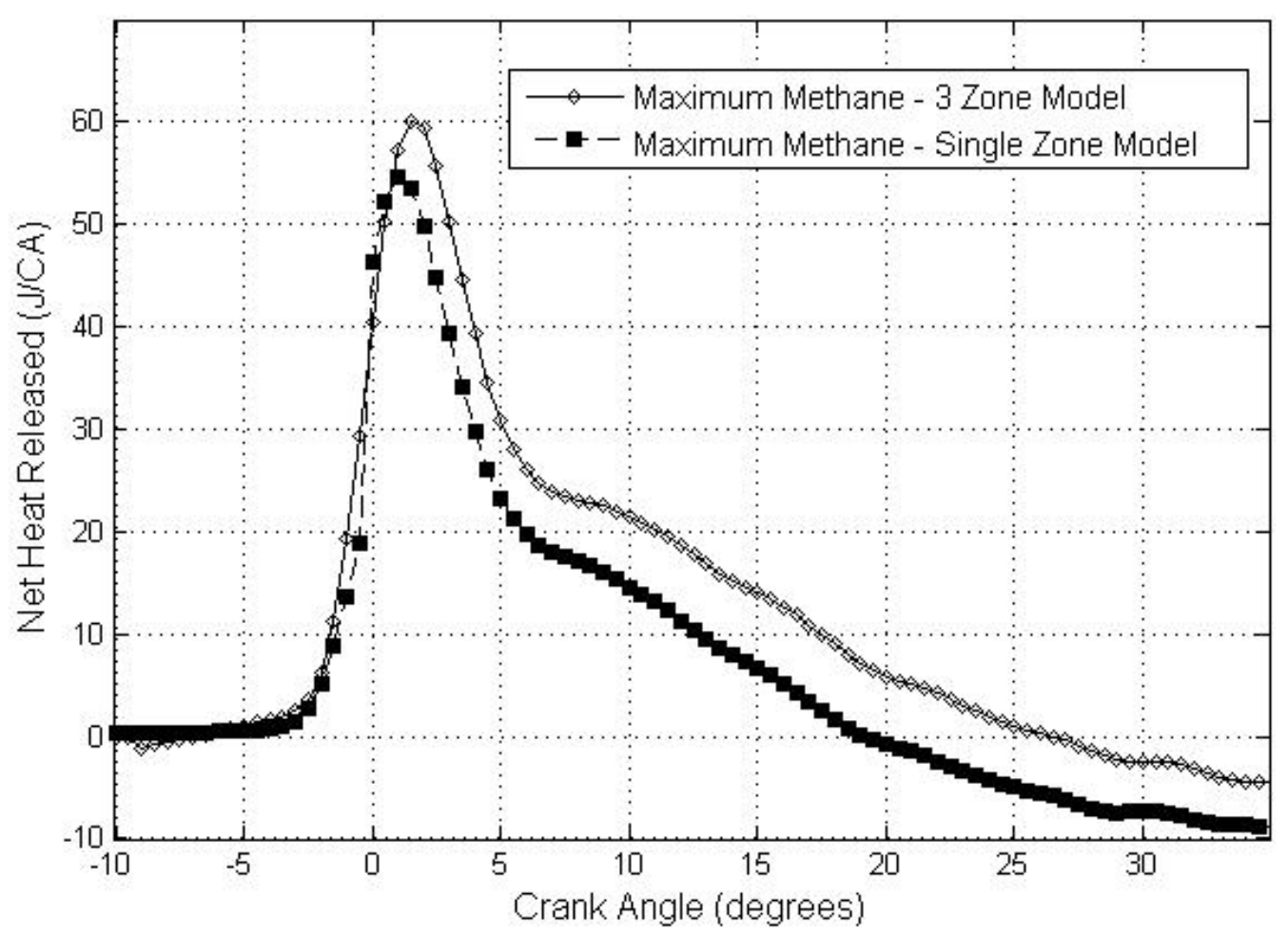

Figure $7 \mathrm{~b}$ - Comparison of the 3-Zone and Experimental Net Heat-Release Rate at 1/4 Load for the Maximum Methane Fuelling Rate 


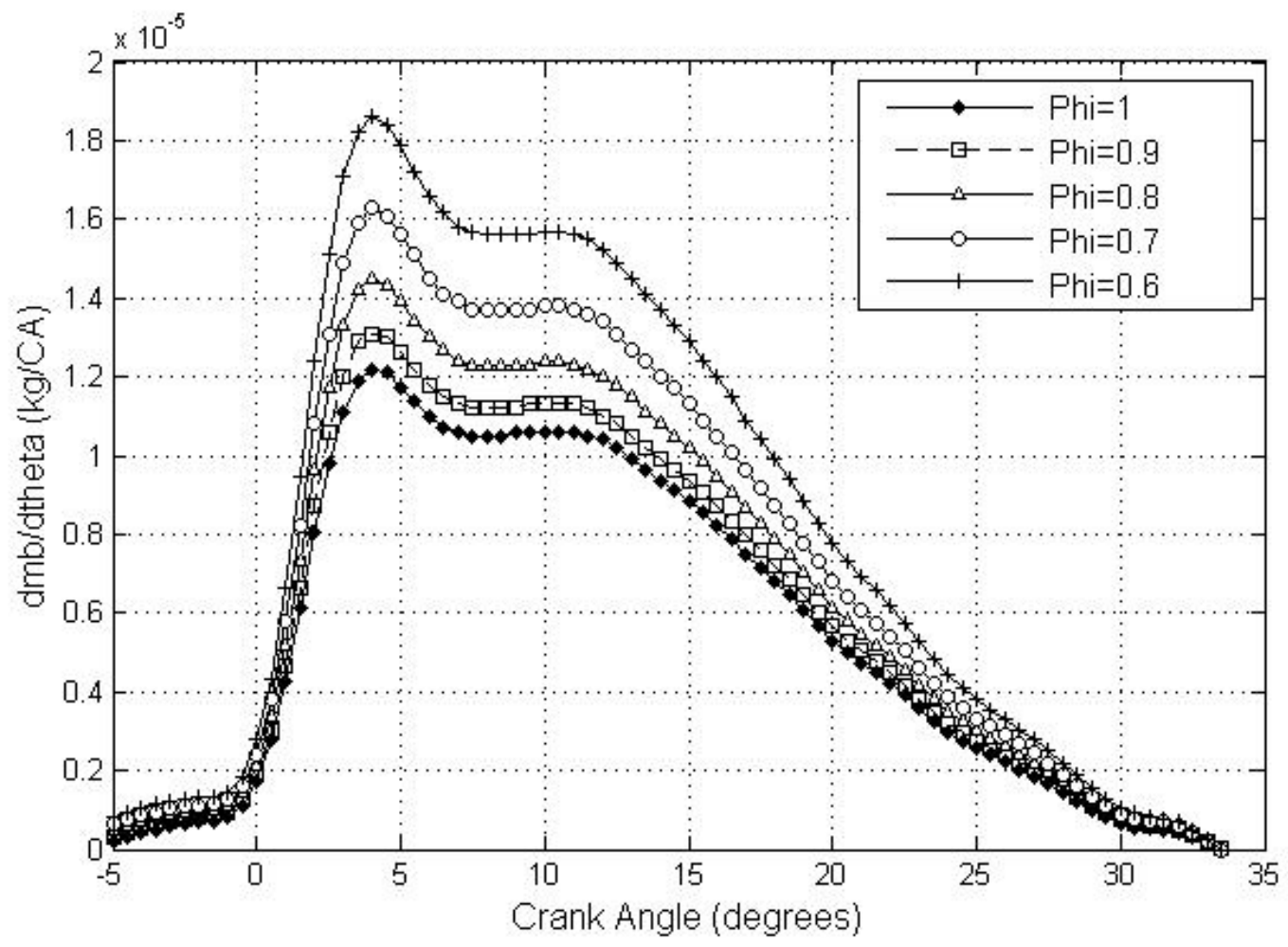

Figure 8a - Comparison of Lean Equivalence Ratios for 82\% Methane Substitution at 1500 rpm and 3/4 Load 


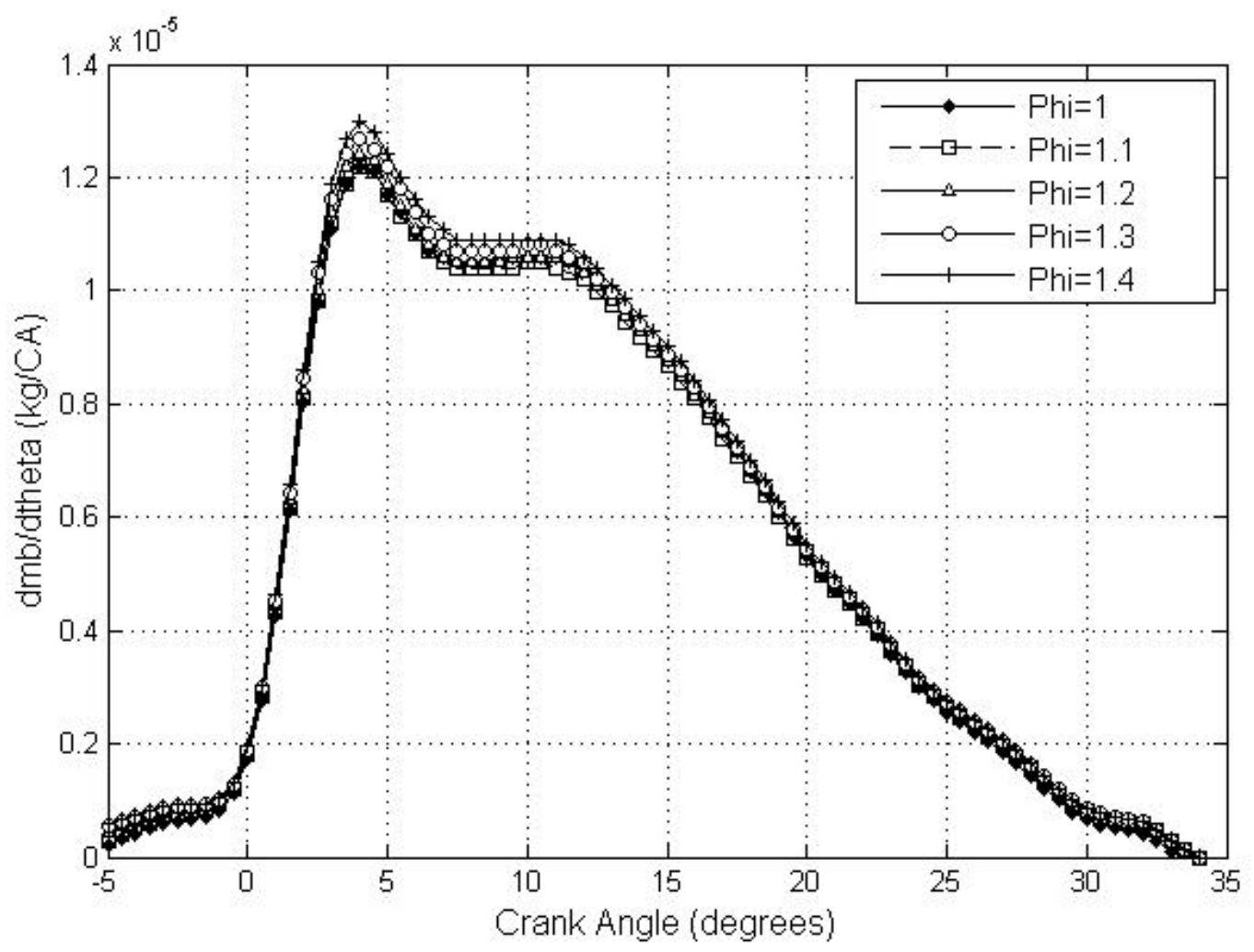

Figure 8b - Comparison of Rich Equivalence Ratios for 82\% Methane Substitution at 1500 rpm and 3/4 Load 


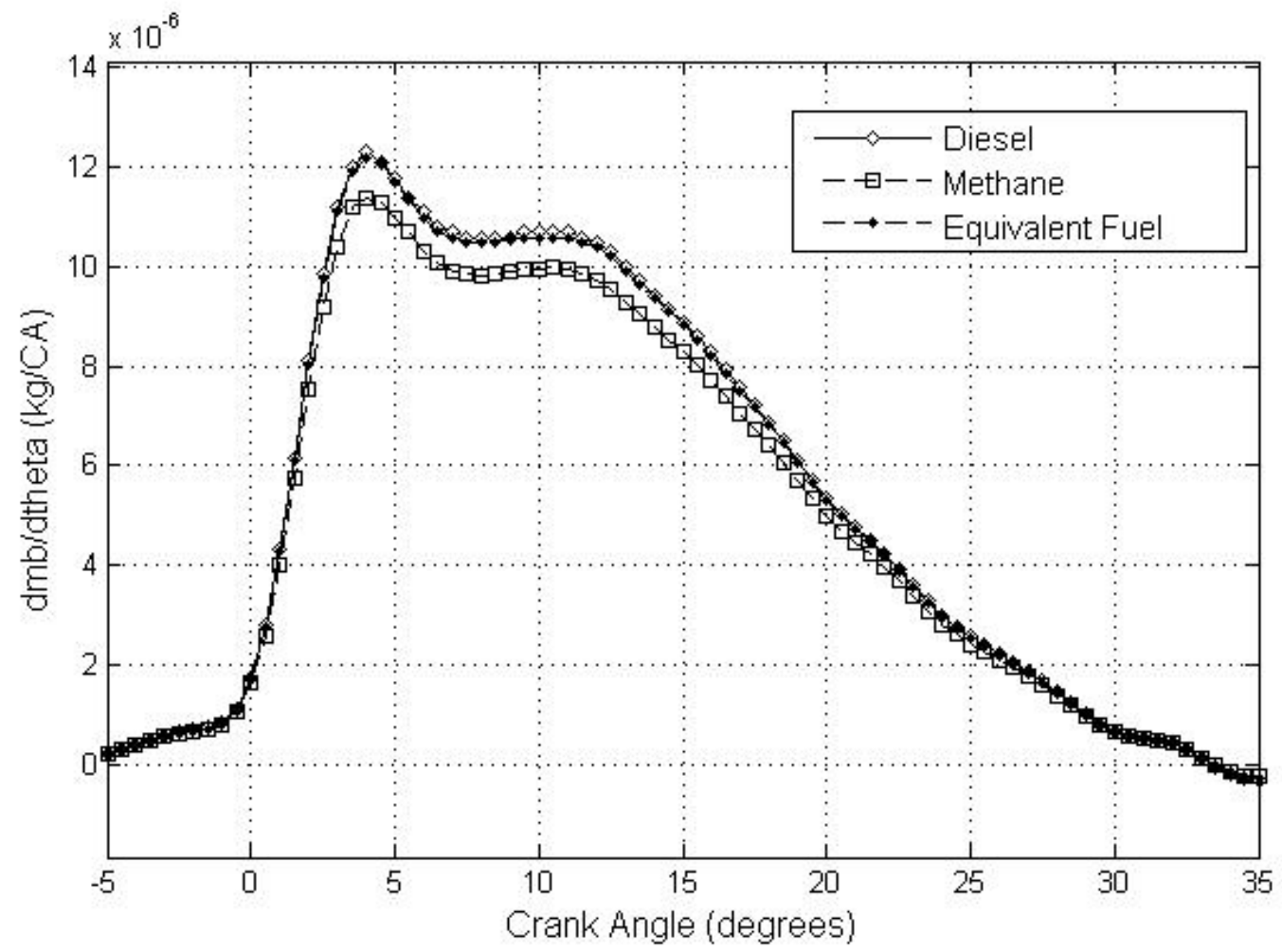

Figure 9 - Comparison of Different Burned Gas Assumptions at 1500 rpm and 3/4 Load for 82\% Methane Substitution 


\begin{tabular}{|c|c|c|}
\hline \multicolumn{3}{|c|}{ NOMENCLATURE } \\
\hline A & Area & $\mathrm{m}^{2}$ \\
\hline$C_{D}$ & Discharge coefficient & $\begin{array}{c}\mathrm{kg} / \\
\mathrm{m}^{2} \mathrm{sec}\end{array}$ \\
\hline $\mathbf{c}_{\mathrm{p}}$ & $\begin{array}{l}\text { Specific heat at } \\
\text { constant pressure }\end{array}$ & $\mathrm{J} / \mathrm{kg}$ \\
\hline $\mathbf{c}_{\mathbf{v}}$ & $\begin{array}{l}\text { specific heat at } \\
\text { constant volume }\end{array}$ & $\mathrm{J} / \mathrm{kg}$ \\
\hline D & Diameter & $\mathrm{m}$ \\
\hline $\mathbf{H}$ & Enthalpy & $\mathrm{J}$ \\
\hline $\mathbf{h}$ & Specific enthalpy & $\mathrm{J} / \mathrm{kg}$ \\
\hline $\mathbf{J}$ & Equivalent-fuel & $\mathrm{kg} / \mathrm{kg}$ \\
\hline MW & Molecular weight & $\mathrm{kg} / \mathrm{kmol}$ \\
\hline $\mathbf{m}$ & Mass & $\mathrm{kg}$ \\
\hline $\mathbf{n}$ & $\begin{array}{l}\text { Polytropic index of } \\
\text { compression }\end{array}$ & - \\
\hline $\mathbf{P}$ & Pressure & $\mathrm{Nm}$ \\
\hline $\mathbf{p}$ & Power & $\mathrm{J} / \mathrm{sec}$ \\
\hline $\mathbf{Q}$ & Heat & $\mathrm{J} / \mathrm{sec}$ \\
\hline $\mathbf{R}$ & Universal gas constant & $\mathrm{J} / \mathrm{kmol.K}$ \\
\hline $\mathbf{r}_{\mathbf{c}}$ & Compression ratio & - \\
\hline $\mathbf{T}$ & Temperature & $\mathrm{K}$ \\
\hline $\mathbf{t}$ & Time & Sec \\
\hline $\mathbf{U}$ & Internal energy & $\mathrm{J}$ \\
\hline $\mathbf{u}$ & $\begin{array}{l}\text { Specific internal } \\
\text { energy }\end{array}$ & $\mathrm{kJ} / \mathrm{kg}$ \\
\hline $\mathbf{V}$ & Volume & $\mathrm{m}^{3}$ \\
\hline W & Work & $\mathrm{J}$ \\
\hline $\mathbf{Y}$ & Mass fraction & - \\
\hline $\mathbf{X}$ & Mole fraction & - \\
\hline$\alpha$ & $\begin{array}{l}\text { Proportion of diesel by } \\
\text { mass }\end{array}$ & - \\
\hline $\boldsymbol{\beta}$ & $\begin{array}{l}\text { Proportion of primary } \\
\text { fuel by mass }\end{array}$ & - \\
\hline$\gamma$ & $\begin{array}{l}\text { Ratio of specific heat } \\
\text { capacities }\end{array}$ & - \\
\hline$\Phi$ & Equivalence ratio & - \\
\hline $\boldsymbol{\theta}$ & Crank angle & Degrees \\
\hline
\end{tabular}




\begin{tabular}{|l|l|}
\hline \multicolumn{2}{|c|}{ SUBSCRIPTS } \\
\hline a & Air \\
\hline atm & Atmospheric \\
\hline b & Burned \\
\hline comb & Combustion \\
\hline cyl & Cylinder \\
\hline d & Diesel \\
\hline df & Dual-fuel \\
\hline eff & Effective \\
\hline $\mathbf{f}$ & Fuel (diesel) \\
\hline fb & Fuel burned \\
\hline fi & Fuel injected \\
\hline fev & Vaporised fuel \\
\hline g & Gaseous fuel \\
\hline i & i $^{\text {th }}$ chemical species \\
\hline $\mathbf{m}$ & manifold \\
\hline o & initial \\
\hline pc & Piston crown \\
\hline T & Total \\
\hline u & Unburned \\
\hline vap & Vaporised \\
\hline w & Wall \\
\hline
\end{tabular}




\begin{tabular}{|l|l|}
\hline \multicolumn{2}{|c|}{ ABBREVIATIONS } \\
\hline AFR & Air to fuel ratio \\
\hline AFRs & Stoichiometric air to fuel ratio \\
\hline BDC & Bottom dead centre \\
\hline CA & Crank angle \\
\hline CI & Compression ignition \\
\hline DI & Direct injection \\
\hline EOC & End of combustion \\
\hline EOI & End of injection \\
\hline IDI & Indirect injection \\
\hline IVC & Inlet valve closure \\
\hline NOx & Oxides of nitrogen \\
\hline SOC & Start of combustion \\
\hline SOI & Start of injection \\
\hline TDC & Top dead centre \\
\hline
\end{tabular}




\begin{tabular}{|l|l|}
\hline Engine Type & DI, 4stroke, naturally aspirated diesel \\
\hline Configuration & Vertical in-line 4 cylinder \\
\hline Cylinder Bore x Stroke & $90 \times 90 \mathrm{~mm}$ \\
\hline Connecting Rod Length & $138 \mathrm{~mm}$ \\
\hline Compression Ratio & $18.5: 1$ \\
\hline Total displacement & 2.29 litres \\
\hline Rated Speed & $1800 \mathrm{rpm}$ \\
\hline Rated Power & $37.5 \mathrm{~kW}$ at $2100 \mathrm{rpm}$ \\
\hline Fuel Injection Pump & Lucas Rotary \\
\hline & \\
\hline
\end{tabular}

Table 1 Engine Specifications. 